\title{
The Frequency of Celiac Disease in Children with Functional Abdominal Pain
}

\author{
Yasin Sahin $^{1 *}$, Derya Aydin Sahin ${ }^{2}$ \\ ${ }^{I}$ Clinics of Pediatric Gastroenterology, Mersin City Training and Research Hospital, Mersin, Turkey \\ ${ }^{2}$ Clinics of Pediatric Cardiology, Mersin City Training and Research Hospital, Mersin, Turkey
}

*Corresponding Author: Yasin Sahin, MD, Clinics of Pediatric Gastroenterology, Mersin City Training and Research Hospital, Mersin, Turkey, Email: ysahin977@gmail.com

\section{Abstract}

Backgrounds/Aim: Chronic abdominal pain (CAP) is a common complaint in children, and there is no underlying organic cause in the majority of cases. It affects 8-17\% of school-aged children. There is no specific diagnostic criteria to distinguish functional abdominal pain (FAP) from organic abdominal pain. Therefore, we aimed to evaluate the frequency of celiac disease $(C D)$ in children with FAP.

Materials and Methods: This retrospective study was conducted between March 2017 and October 2018 and included 100 patients with functional abdominal pain. Total IgA and tissue transglutaminase antibody ( $t T G$ IgA levels were analyzed. Gastroduodenoscopy was performed on patients with positive tTG.

Results: One hundred patients with FAP (58 female) with mean age of $8.6 \pm 3.7$ years were included. None of the patients had IgA deficiency. Only three of 100 patients (3\%) was positive for $t T G$ IgA. One of them did not accept the gastroduodenoscopy. Gastroduodenoscopy was performed on two patients positive for tTG IgA. According to the pathologic results, only one patient had Marsh $3 b$ classification score compatible with CD.

Conclusion: One patient (1\%) of 100 patients with FAP was found to have CD. According to our results, we suggest that children with FAP should be examined for CD. However, there is a need for multicentric studies that would support our findings.

Keywords: celiac disease, children, functional abdominal pain, intestinal biopsy

Chronic abdominal pain (CAP) is a common complaint in children and adolescents, and there is no underlying organic cause in the majority of cases. It affects $8-17 \%$ of school-aged children (1).

The Rome III criteria is a symptom-based classification used for functional gastrointestinal diseases (FGIDs) in children aged 4 to 18 years. Functional abdominal pain (FAP) is classified as abdominal pain, which occurs at least once a week for at least two months in childhood and there is no organic cause to explain the patient's symptoms before the diagnosis according to Rome III criteria. It can be episodic or continuous (2). There is no specific diagnostic criteria to distinguish FAP from organic abdominal pain, and further investigations are generally not recommended in the absence of alarm symptoms and findings (1).

It has been shown that the Rome III criteria are insufficient to distinguish FAP from organic diseases $(3,4)$. An organic disease was diagnosed in 21 (29\%) of 73 patients who was diagnosed with FAP according to the Rome III criteria (3).

Celiac disease is an immune-mediated systemic disease characterized by variable combination of clinical manifestations and enteropathy triggered by gluten ingestion in genetically susceptible individuals (5). Celiac disease may present with malabsorbtion symptoms such as chronic diarrhea or may present with various extraintestinal symptoms such as increased liver enzymes, anemia and short stature. CD can also be diagnosed in children with vague symptoms such as chronic abdominal pain, abdominal distention or constipation. $90 \%$ of the affected individuals remains undiagnosed $(5,6)$. The variable clinical findings of $C D$ are both genetic and immunologically based, and also the onset age of the disease may affect the clinics (7). 
The diagnosis of $\mathrm{CD}$ at the time can prevent the complications of chronic diseases such as osteoporosis, infertility and small bowel cancer in affected individuals (8).

Even though abdominal pain is one of the symptoms of $\mathrm{CD}$, routinely serological screening tests for CD are not recommended in these children (9). However, it is recommended that serologic tests for celiac disease should be done in patients with persistent gastrointestinal symptoms such as recurrent abdominal pain, vomiting, constipation (10).

In this study we aimed to evaluate the frequency of $\mathrm{CD}$ in children with FAP.

\section{Material ANd Methods}

This study was retrospectively conducted between March 2017 and October 2018. This study protocol was approved by the Ethical Committee of Mersin University.

The children aged 4-18 years who were referred to pediatric gastroenterology outpatient clinics with chronic abdominal pain and diagnosed with functional abdominal pain according to the Roma III criteria were included in the study (11). According to Rome III criteria, patients with alarm symptoms such as abdominal pain in the right quadrant, dysphagia, vomiting, blood in stool, weight loss, growth retardation, fever, chronic diarrhea or positive family history of inflammatory bowel disease were excluded from the study (2). In addition, those who had previously diagnosed $\mathrm{CD}$, positive family history for $\mathrm{CD}$, and diseases associated with $\mathrm{CD}$ were not included in the study. All patients were initially evaluated with tissue transglutaminase (tTG) IgA antibody and total IgA test. The cutoff value of tTG IgA antibody was $20 \mathrm{U} / \mathrm{ml}$.

Gastroduodenoscopy was performed on patients with tTG positivity. At least 4 biopsies from duodenum and 2 from bulbus were taken. The latest ESPGHAN and NASPGHAN guidelines recommend that at least 4 biopsies from the duodenum and one biopsy from bulbus should be taken endoscopically in case of suspectivity of $\mathrm{CD}$ because of the patchy involvement $(5,12)$.

Biopsies were evaluated according to the Marsh classification criteria for the diagnosis of CD (13).

\section{Statistical Analysis}

Descriptive statistics were used for frequency, percentage, and mean \pm standard deviation. Statistical Package for Social Sciences for
Windows, version 22.0 software (SPSS Inc, Chicago IL, USA) was used for statistical analysis. $\mathrm{P}$ value $<0.05$ was considered as significant.

\section{Results}

Of the 100 patients included in the study, 58 of them $(58 \%)$ was female. The mean age of patients was $8.6 \pm 3.7$ years. The mean tTG levels was $6.2 \pm 11.3 \mathrm{U} / \mathrm{ml}$ (Table 1 ).

Table1. The laboratory and demographic features of the patients

\begin{tabular}{|l|l|}
\hline \multicolumn{2}{|c|}{ The laboratory and demographic features of } \\
Patients $(\mathbf{n}=\mathbf{1 0 0})$ \\
\hline & $8.6 \pm 3.7$ \\
\hline Age $($ years $)$ & $58 / 42$ \\
\hline Sex $($ female/male) & $6.2 \pm 11.3$ \\
\hline tTG IgA $(\mathrm{U} / \mathrm{ml})$ & $135.6 \pm 64.1$ \\
\hline Total IgA $(\mathrm{mg} / \mathrm{dl})$ & $12.7 \pm 1.0$ \\
\hline Hemoglobin $(\mathrm{g} / \mathrm{dL})$ & $28.0 \pm 8.3$ \\
\hline AST & $16.4 \pm 5.4$ \\
\hline ALT & \\
\hline
\end{tabular}

$\operatorname{IgA}$ deficiency was not detected in any patients. Three patients (3\%) had positive for tTG IgA. One of them did not accept the gastroduodenoscopy. Gastroduodenoscopy was performed on two patients with tTG IgA positivity. Four biopsies from duodenum and two biopsies from bulb was taken. Marsh 0 classification score was detected in one of them, and the other one had Marsh 3b classification score. According to Marsh classification score, the latter result of pathology was compatible with CD (Table 2). The frequency of biopsyproven celiac disease was found to be $1 \%$.

Table2. The laboratory data of patients who had tissue transglutaminase antibody positivity

\begin{tabular}{|l|l|l|l|}
\hline $\begin{array}{c}\text { Patient } \\
\text { no }\end{array}$ & $\begin{array}{c}\text { tTG IgA } \\
(\mathbf{U} / \mathbf{m l})\end{array}$ & $\begin{array}{c}\text { Total IgA } \\
(\mathbf{m g} / \mathbf{d l})\end{array}$ & Pathology \\
\hline 1 & 110 & 143 & Marsh 3b \\
\hline 2 & 37.1 & 201 & Marsh 0 \\
\hline $3^{*}$ & 20.7 & 115 & - \\
\hline
\end{tabular}

$t T G=$ tissue transglutaminase

*The patient did not accept the gastroduodenoscopy

\section{DISCUSSION}

Functional abdominal pain is one of the most common FGIDs of childhood. FAP is frequently localized in the periumblical region and is usually not associated with diarrhea, vomiting, weight loss, night symptoms or growth retardation. Inflammatory, anatomic and metabolic diseases should be ruled out before the diagnosis of FAP. Therefore, it is inevitable to conduct a diagnostic test. There is no 
evidence-based guidelines regarding which tests are useful and which organic diseases must be rule out before diagnosis of FAP (14).

The pathogenesis of FGID-associated abdominal pain is not fully understood (15).

Celiac disease is the most common disease in Western Europe and North America, with a prevalence of approximately $1 \%$ (16). In the last few decades, the frequency of $\mathrm{CD}$ is increasing. The reasons for this are the widespread use of sensitive serologic tests, increasing awareness of $\mathrm{CD}$ among families and health personnels and screening of high-risk patients (17).

Celiac disease may present with a wide range of clinical manifestations. Classic symptoms include gastrointestinal system (GIS) symptoms such as chronic diarrhea, weight loss, and growth retardation (8). The atypical form is characterized by extraintestinal symtoms. These include iron deficiency anemia, abdominal distention, constipation, chronic fatigue, headache, abdominal pain and osteoporosis.

Although the last ESPGHAN guideline published in 2012 suggests CD screening tests for children with unexplained CAP, routine screening tests for $\mathrm{CD}$ are not widely accepted in practice because chronic abdominal pain is very common in childhood $(5,18,19)$.

It is not clear that CAP is a marker of CD, because recurrent abdominal pain is more common in children. In children with $C D$ there is a change from GIS symptoms to extraintestinal symptoms (5). Because of the increasing awareness of $\mathrm{CD}$, it is unclear whether the chronic abdominal pain reflects a true clinical variation or better recognition of non-gastrointestinal forms of CD (5).

In celiac disease, abdominal pain is a common symptom (43-90\%), it can be seen alone without any other symptoms, and rapidly grows with the gluten-free diet $(5,7,20-22)$.

There is limited information about the potential association between FAP and CD in children. There is insufficient evidence to perform routine screening tests for $\mathrm{CD}$ in children with chronic abdominal pain in previous studies $(18,23-26)$.

In some studies, the prevalence of $\mathrm{CD}$ in children with CAP was detected similar to the general population $(9,23-26)$.

Conversely, there are also studies reporting that the prevalence of CD in children with CAP is higher than expected in the general population $(1.3-3.9 \%)(18,27-30)$.
In a recent large population-based CD screening study, CD-associated symptoms including abdominal pain were interrogated prior to serological tests. There was no significant difference in $\mathrm{CD}$ prevalence between children with and without any celiac disease-associated symptoms (31).

In a single-center retrospective study, the incidence of $\mathrm{CD}$ was found to have higher incidence in children with chronic abdominal pain than in the general population (18). However, patients with comorbidities were not excluded from the study. The prevalence of CD was detected as $4.9 \%$ in 82 patients with CAP. In this study, authors suggested that children with CAP having additional GI symptoms should be careful in terms of screening for $\mathrm{CD}$.

In an another study, serologic tests for CD were performed in 127 of 151 patients with recurrent abdominal pain. Gastroduodenoscopy was performed on $8(6.2 \%)$ patients with tTG positivity, and $5(3.9 \%)$ of these patients were diagnosed with $\mathrm{CD}$. Three of those patients had no clinical signs other than abdominal pain (28).

With increasing awareness about various clinical findings of $\mathrm{CD}$ and availability of reliable serologic tests allows early diagnosis of atypical forms compared to previous studies (32).

The rate of patients with $\mathrm{CD}$ presenting with abdominal pain ranges from $19.4 \%$ to $90 \%$ (20,32-34).

1047 children (mean age 9.6 \pm 4.1 years) with CAP were evaluated in Turkey (9). Patients were assessed according to Roma III criteria. Those with alarm semptoms and those with $\mathrm{CD}$ were excluded from the study. All patients were assessed by rapid tTG test, positive patients were examined by tTG -ELISA and gastroduodenoscopy was performed on positive cases. Rapid tTG positivity was detected in 13 patients, tTG ELISA was positive in 10 of them, endoscopy was performed on 10 patients and $\mathrm{CD}$ was detected in all of them. The prevalence of CD in FAP was found a similar prevalence to that in the general population (9).

The main clinical manifestations of $\mathrm{CD}$ are diarrhea and abdominal bloating in younger children. Although abdominal pain is more common in older children with $\mathrm{CD}$, there is no association between classic abdominal pain and CD (26). 
Letizia et al. reported that recurrent abdominal pain is seen in $43 \%$ of patients with CD (35). Although recurrent abdominal pain is often reported in $\mathrm{CD}$, celiac screening tests are not currently recommended in children with recurrent abdominal pain $(19,26)$.

In a multicenter study from Turkey including healthy children between the ages of 6-17, the prevalence of $\mathrm{CD}$ was found to be $0.47 \%$ (36). According to our study results, the prevalence of $\mathrm{CD}$ in children with FAP was two times $(1.0 \%)$ higher than in the general population of Turkey.

\section{LiMitATIONS OF THE STUDY}

The first limitation is that there was a small number of case. Second, since our study was retrospective, we don't know how many grams of gluten patients consume in a day. Third, one of the patients with tTG positivity did not accept gastroduodenoscopy. If this patient was diagnosed with celiac disease by biopsy, the frequency of biopsy-proven celiac disease would be $2 \%$. Therefore, the effectiveness of the present study may be weak.

Celiac disease may commonly present with malabsorbtion symptoms. It is important that $\mathrm{CD}$ is diagnosed not only in children with significant gastrointestinal symptoms but also in children with vague clinical signs, as the disease may have negative effects on health. In the absence of typical diarrhea, many cases with CD may be skipped and non-classical CD may not be diagnosed (37).

As a result, the frequency of $\mathrm{CD}$ in children with FAP was found to be two times higher than in general population. We suggest that children with FAP should be examined for CD. However, multicentric studies with higher number of patients are needed in order to provide a more reliable data.

\section{REFERENCES}

[1] Di Lorenzo C, Colletti RB, Lehmann HP, et al. Chronic abdominal pain in children: a technical report of the american academy of pediatrics and the North American Society for Pediatric Gastroenterology, Hepatology and Nutrition. J Pediatr Gastroenterol Nutr 2005; 40: 249-61.

[2] Rasquin A, Di Lorenzo C, Forbes D, et al. Childhood functional gastrointestinal disorders: child/adolescent. Gastroenterology 2006; 130: 1527-37.

[3] Gijsbers CF, Benninga MA, Schweizer ZZ, Kneepkens CM, Vergouwe Y, Büller HA. Validation of the Rome III criteria and alarm symptoms for recurrent abdominal pain in children. J Pediatr Gastroenterol Nutr 2014; 58: 779-85.

[4] Helgeland H, Flagstad G, Grotta J, et al. Diagnosing pediatric functional abdominal pain in children (4-15 years old) according to the Rome III criteria: results from a Norwegian prospective study. J Pediatr Gastroenterol Nutr 2009; 49: 309-15.

[5] Husby S, Koletzko S, Korponay-Szabo IR, et al. ESPGHAN guidelines for the diagnosis celiac disease in children and adolescents: an evidence-based approach. J Pediatr Gastroenterol Nutr 2012; 54: 136-60.

[6] Ravikumara M, Nootigattu VKT, Sandhu BK. Ninety percent of coeliac disease is being missed. J Pediatr Gastroenterol Nutr 2007; 45: 497-9.

[7] Oliviera GN, Mohan R, Fagbemi A. Review of celiac disease presentation in a pediatric tertiary centre. Arq Gastroenterol 2018; 55: 86-93.

[8] Downey L, Houten R, Murch S, Longson D, Guideline Development Group. Recognition, assessment, and management of coeliac disease: summary of updated NICE guidance. BMJ 2015; 351: h4513.

[9] Kansu A, Kuloğlu Z, Demir A, Yaman A, Turkish Celiac Study Group. Yield of coeliac screening in abdominal pain-associated functional gastrointestinal system disorders. J Paediatr Child Health 2015; 51: 1066-70.

[10] Hill ID, Dirks MH, Liptak GS, et al. Guideline for the diagnosis and treatment of celiac disease in children: recommendations of the North American Society for Pediatric Gastroenterology, Hepatology and Nutrition. J Pediatr Gastroenterol Nutr 2005; 40: 1-19.

[11] Drossman DA. The functional gastrointestinal disorders and the Rome III process. Gastroenterology 2006; 130: 1377-90.

[12] Hill ID, Fasano A, Guandalini S, et al. NASPGHAN clinical report on the diagnosis and treatment of gluten-related disorders. J Pediatr Gastroenterol Nutr 2016; 63: 156-65.

[13] Marsh MN. Gluten, major histocompatibility complex, and the small intestine: a molecular and immunobiologic approach to the spectrum of gluten sensitivity (celiac sprue). Gastroenterology 1992; 102: 330-54.

[14] Sood MR, Matta SR. Approach to a child with functional abdominal pain. Indian $\mathbf{J}$ Pediatr 2016; 83: 1452-8.

[15] Cremon C, Gargeno L, Morselli-Lobate AM, et al. Mucosal immune activation in irritable bowel syndrome: gender dependence and association with digestive symptoms. Am J Gastroenterol 2009; 104: 392-400.

[16] Shannahan S, Leffler DA. Diagnosis and Updates in Celiac Disease. Gastrointest Endosc Clin N Am 2017; 27: 79-92. 
[17] Guandalini S. The approach to celiac disease in children. Int J Pediatr Adolesc Med 2017; 4: 124-7.

[18] Chumpitazi BP, Mysore K, Tsai CMW, et al. Interprovider variation of coeliac disease testing in childhood chronic abdominal pain. BMC Gastroenterol 2013; 13: 150.

[19] Saps M, Sansotta N, Bingham S, et al. Abdominal pain-associated functional gastrointestinal disorder prevalence in children and adolescents with celiac disease on glutenfree diet: A multinational study. J Pediatr 2017; 182: $150-4$

[20] Rashid M, Cranney A, Zarkadas M, et al. Celiac disease: evaluation of the diagnosis and dietary compliance in Canadian children. Pediatrics 2005; 116: e754-9.

[21] Murray JA, Watson T, Clearman B, Mitros F. Effect of a gluten-free diet on gastrointestinal symptoms in celiac disease. Am J Clin Nutr 2004; 79: 669-73.

[22] Aziz DA, Kahlid M, Memon F, Sadiq K. Spectrum of $\mathrm{CD}$ in paediatric population: experience of tertiary care center from Pakistan. Pak J Med Sci 2017; 33: 1301-6.

[23] Gijbers CF, Benninga M, Büller H. Clinical and laboratory findings in 220 children with recurrent abdominal pain. Acta Paediatr 2011; 100: 1028-32.

[24] Dhroove G, Chogle A, Saps M. A milliondollar work-up for abdominal pain: is it worth it? J Pediatr Gastroenterol Nutr 2010; 51: 57983 .

[25] Thakkar K, Chen L, Tessier ME, Gilger MA. Outcomes of children after esophagogastroduodenoscopy for chronic abdominal pain. Clin Gastroenterol Hepatol 2014; 12: 963-9.

[26] Fitzpatrick KP, Sherman PM, Ipp M, et al. Screening for coeliac disease in children with recurrent abdominal pain. J Pediatr Gastroenterol Nutr 2001; 33: 250-2.

[27] El-Matary W, Spray C, Sandhu B. Irritable bowel syndrome: the commonest cause of recurrent abdominal pain in children. Eur $\mathrm{J}$ Pediatr 2004; 163: 584-8.

[28] Kırsaçlıoğlu CT, Kuloğlu Z, Üstündağ G, Ensari A, Kansu A. Çocuklarda Tekrarlayan Karın Ağrısı: Organik mi, Fonksiyonel mi? Türkiye Klinikleri Journal of Pediatrics 2006; 25: 74-81.

[29] Saltik IN, Kocak N, Yüce A, Gürakan F. Celiac disease screening of Turkish children with recurrent abdominal pain. J Pediatr Gastroenterol Nutr 2002; 34: 424.

[30] Farahmand F, Modaresi V, Najafi M, Khodadad A, Moetamed F, Modarres Z. Prevalence of celiac disease in Iranian children with recurrent abdominal pain referred to a pediatric referral center. Iran J Pediatr 2011; 21: 33-8.

[31] Rosen A, Sandström O, Carlsson A, et al. Usefulness of symptoms to screen for coeliac disease. Pediatrics 2014; 133: 211-18.

[32] Rawai P, Thapa BR, Nain CK, Prasad KK, Singh K. Changing spectrum of CD in India. Iran J Pediatr 2010; 20: 459-65.

[33] Patwari AK, Anand VK, Kapur G, et al. Clinical and nutritional profile of children with celiac disease. Indian Pediatr 2003; 40: 337-42.

[34] Poddar U, Thapa BR, Singh K. Clinical features of celiac disease in Indian children: Are they different from the West? J Pediatr Gastroenterol Nutr 2006; 43: 313-7.

[35] Letizia M, Tolone C, Belfiore I, et al. Recurrent abdominal pain and celiac disease. Dig Liver Dis 2013; 45: e288.

[36] Dalgic B, Sari S, Basturk B, et al. Turkish Celiac Study Group. Prevelance of celiac disease in healthy Turkish school children. Am J Gastroenterol 2011; 106: 1512-7.

[37] Hashmi MA, Hussain T, Masood N, Younas M, Asghar RM, Shafi MS. Accuracy of antitissue transglutaminase IgA antibody in the diagnosis of paediatric celiac disease. J Coll Physicians Surg Pak 2016; 26: 263-6.

Citation: Yasin Sahin, Derya Aydin Sahin, The Frequency of Celiac Disease in Children with Functional Abdominal Pain. ARC Journal of Pediatrics. 2018; 4(2): 1-5. doi:dx.doi.org/10.20431/2455-5711.0402001.

Copyright:(C) 2018 Authors. This is an open-access article distributed under the terms of the Creative Commons Attribution License, which permits unrestricted use, distribution, and reproduction in any medium, provided the original author and source are credited. 